\title{
SLUTWALK, FEMINISM, ACTIVISM AND MEDIA
}

Resenha: Kaitlynn Mendes. 2015. London: Palgrave Macmillan, 232 pp.

\section{Rui Vieira Cruz}

Centro Interdisciplinar em Ciências Sociais da Universidade do Minho (CICS.Nova/UMinho). Centro de Estudos em Comunicação e Sociedade da Universidade do Minho (CECS/UMinho). Email:

\author{
rmvcruz@gmail.com
}

"Women should avoid dressing like sluts" - "As mulheres devem evitar vestir-se como galdérias". Foi esta frase, proferida por um agente de segurança canadiano durante uma intervenção na Universidade de Toronto, que deu o mote para a ampla discussão nas redes sociais online sobre a perpetuação dos mitos da violação. A tónica constante nas mulheres que se vestem de forma considerada provocante, consomem álcool ou manifestam interesse por sexo resulta regulamente na sua culpabilização pelos crimes sexuais de que são vítimas. Este imaginário, aliado à (falsa) imagética social de que as violações ocorrem em becos escuros e perpetrados por alguns vândalos incapazes de controlar a sua libido e luxúria, abriu espaço para a discussão sobre a violência sexual e para a

\footnotetext{
${ }^{1} \mathrm{O}$ protesto ficou conhecido como 'Marcha das

Galdérias' em Portugal e 'Marcha das Vadias' no Brasil.
}

realização das marchas de protesto SlutWalk', unidas pelo slogan "Because We've Had Enough". De que forma é que sair às ruas com a palavra slut escrita nos corpos e/ou em cartazes alerta para a cultura da violação? São estes os tópicos que, na esteira dos estudos dos média e da comunicação, Mendes analisa em oito países $^{2}$ ao longo do seu livro.

Estruturado em oito capítulos, o livro aborda i) a introdução ao tema; ii) a contextualização do movimento SlutWalk; iii) a implementação da SlutWalk no espaço geográfico e temporal; iv) o modo como a SlutWalk desafiou a cultura da violação; v) as controvérsias e objeções; vi) as hierarquias e os papéis das organizações participantes; vii) a ligação das comunidades SlutWalk ao

\footnotetext{
2 África do Sul, Austrália, Canadá, Estados Unidos, Índia, Nova Zelândia, Reino Unido e Singapura.
} 


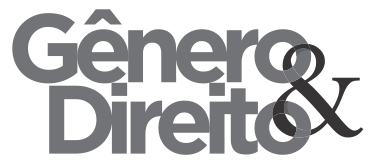

ciberativismo; e viii) a sistematização final.

No capítulo 1 (introdução), Mendes questiona e rejeita a premissa de que a violência sexual é um ato genético/biológico, apresentando para isso um conjunto de dados que revela a discrepância global no que concerne ao número de violações reportadas. É esta variabilidade que, aliada às formas como ocorre, torna esta prática num fenómeno social e valida o surgimento da SlutWalk como um movimento que visa a (auto)determinação das mulheres sobre o seu corpo, a sua livre participação no espaço público e o fim da cultura da violação.

No capítulo 2, dedicado à revisão da literatura e ao enquadramento conceptual, deparamo-nos com uma análise centrada numa tríade entre (pós)feminismo(s), representação e social media. É também neste capítulo que são focados os aspetos metodológicos que guiam a investigação: esta baseou-se em técnicas complementares de índole qualitativa (i.e, análise de conteúdo, análise de enquadramento e análise crítica do discurso), incluiu recortes de imprensa internacional e envolveu a realização de
Periódico do Núcleo de Estudos e Pesquisas sobre Gênero e Direito Centro de Ciências Jurídicas - Universidade Federal da Paraíba V. 6 - Nº 01 - Ano 2017 - Mídia, Gênero \& Direitos Humanos ISN | 2179-7137 | http://periodicos.ufpb.br/ojs2/index.php/ged/index

entrevistas semi-estruturadas. O seu cariz inovador consistiu na netnografia (i.e., etnografia na internet) ao acompanhar as discussões geradas no seio dos grupos nos espaços online e na participação nas marchas de protesto (que foram, posteriormente, relatadas em formato de registo etnográfico).

Mas que tipo de cobertura mediática foi feita? E onde ocorreram estes protestos? Foi no capítulo 3 que Mendes situou territorial, espacial e ideologicamente estas respostas e explorou as variações regionais, nacionais e internacionais no que concerne ao acompanhamento realizado pelos média mainstream e pelos média feministas sobre a SlutWalk, no período compreendido entre 7 de fevereiro de 2011 e 31 de dezembro de 2013. Com forte presença mediática em 2011, os dois anos seguintes notaram uma redução drástica, revelando uma fadiga temática e o término do efeito de espectacularização da SlutWalk, o que não impediu, porém, a expansão global do movimento e as consequentes adaptações regionais. Contudo, diversas organizações encararam a SlutWalk como um retrocesso nos avanços conquistados pelos movimentos feministas nas últimas 


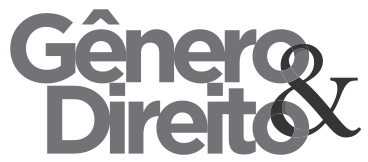

décadas e uma mera adaptação da realidade do Canadá e dos EUA. Em países como a Austrália, a Nova Zelândia e sobretudo a Índia, o movimento SlutWalk foi acusado de apaziguar o Ocidente, de não ter em consideração os trajetos diferenciados do feminismo nestes contextos e de relegar as especificidades destes países, onde a violência sexual é um problema sistémico e está aliada ao sistema de classe/castas. Mas existiram, contudo, algumas práticas diferenciadas entre países. Em Singapura, devido ao controlo estatal e policial e à proibição de protestos públicos, a tradicional marcha SlutWalk não decorreu, o que deu azo a outras estratégias de divulgação (e.g., workshops e slutscreens). Por sua vez, no Canadá e nos EUA, outra questão pertinente incidiu sobre o "reclamar", ou não, da palavra slut. Vários movimentos negros criticaram a sua utilização acusando de ser uma palavra somente usada contra mulheres brancas. Estes discursos suscitaram uma ampla discussão no seio do movimento SlutWalk e do movimento feminista em grupos de mulheres negras que não se reviam na palavra slut (preferindo a expressão ho), exigindo o seu re-branding e re-labeling.
Periódico do Núcleo de Estudos e Pesquisas sobre Gênero e Direito Centro de Ciências Jurídicas - Universidade Federal da Paraíba V. 6 - Nº 01 - Ano 2017 - Mídia, Gênero \& Direitos Humanos SSN | 2179-7137 | http://periodicos.ufpb.br/ojs2/index.php/ged/index

As plataformas organizadas da SlutWalk de Toronto e de Winnipeg rejeitaram esta proposta; a SlutWalk Vancouver realizou uma assembleia aberta online para discutir a temática, acabando por decidir manter o nome; em outros grupos, como a SlutWalk Chicago e Filadélfia, a expressão SlutWalk acabou por cair. Em Joanesburgo, que manteve a expressão slut, foi decidido que os indivíduos não precisavam de se identificar com a palavra para fazerem parte do movimento.

Tiveram, contudo, os média atenção às preocupações emergentes na discussão interna? Mendes responde a esta questão no capítulo 4, no qual explorou o enquadramento dado às ações da SlutWalk pelos média mainstream e pelos média feministas. A forma como a SlutWalk desafiou e alertou para a violência sexual foi o foco principal destacado pelos média mainstream e feministas. Contudo, o livro não analisa apenas a diferença nas mensagens, mas também os conteúdos que os diversos grupos pretenderam ver transmitidos. Este desfasamento recorrente - entre o que se pretende transmitir e o que é efetivamente transmitido - abriu espaço para a crítica teórica que Mendes faz de ambos os tipos 


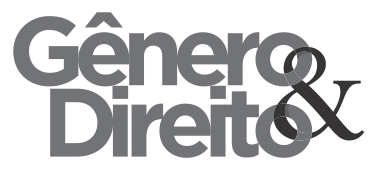

de média. Se inicialmente são captadas as estratégias de culpabilização do violador, também são analisadas as estratégias discursivas utilizadas para culpar a vítima, sobretudo nos média mainstream. A obra ironiza até com as estratégias discursivas que focam peças de roupa de tal forma provocantes que tornam as pessoas que as usam "violáveis". Desconstruindo e retirando o valor discursivo deste tipo de registos e ancorada numa abordagem que abandona a "pessoalização" da vítima, rejeitando as características individualizadas (i.e., o que veste, a forma como se veste, se consome álcool, se sai à noite), Mendes incide numa vertente estrutural do problema: a violação como forma de violência, de poder e de controlo que ocorre em períodos de conflito bélico (independentemente da indumentária da vítima); como forma de punição e vingança (revenge rape); e como forma de gratificação sexual no qual os desejos e as fantasias do violador ultrapassam a autonomia do corpo da vítima (date rape).

A pertinência do alerta para as dimensões da violência sexual não isentou a SlutWalk de sofrer oposições. No capítulo 5, o livro capta as controvérsias e as objeções dirigidas às tácticas e objetivos
Periódico do Núcleo de Estudos e Pesquisas sobre Gênero e Direito Centro de Ciências Jurídicas - Universidade Federal da Paraíba V. 6 - Nº 01 - Ano 2017 - Mídia, Gênero \& Direitos Humanos SSN | 2179-7137 | http://periodicos.ufpb.br/ojs2/index.php/ged/index

da SlutWalk, nomeadamente aquelas que endereçam o(s) uso(s) do corpo. As críticas incidiram na possibilidade de apoiar a temática sem apoiar as formas de execução. A incorporação nos conteúdos de divulgação e nos protestos SlutWalk de imagens de mulheres jovens, magras e sensuais conferiu ao movimento uma lente e um apelo ao male gaze, transformando uma ação de consciencialização para a violência sexual num ato de espectacularização, o corpo em fetichismo da mercadoria, advindo daí o interesse dos média mainstream. Este foco no corpo, no choque e na espetacularização que os média mainstream atribuíam ao protesto levantou amplas críticas por parte das organizações envolvidas na SlutWalk, acusando-os de representar erroneamente as marchas de protesto. Mendes afasta-se da dualidade entre o bem e o mal e não considera que a SlutWalk tenha sido mal representada pelos média mainstream, uma vez que estes apenas apresentaram uma moldura interpretativa assente num quadro ideológico neoliberal. No entanto, o destaque dado à espectacularização através de imagens/fotos/vídeos tentou, na ótica das organizações e participantes, desvirtuar a vertente sex-positive do 


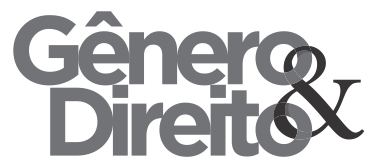

movimento. Este facto redirecionou os movimentos feministas para uma atuação mais criativa e para uma narrativa que não incidisse no ideário neoliberal. $\mathrm{O}$ seu foco não se baseou em queixas ou reclamações, mas em intervir diretamente ao oferecer outra moldura interpretativa para compreender, representar e lembrar o movimento. Os coletivos feministas tentaram, pois, gerar contra-memórias através de vídeos, fotos e textos capazes de combater a voz hegemónica dos média mainstream. Todavia, a SlutWalk apresentava um conjunto de incoerências internas: ela própria aparecia ligada aos princípios neoliberais através da defesa da individualização no controlo do corpo e promovia uma vertente apolítica e nãoestrutural. As críticas feministas ao próprio movimento, que endereçavam a incidência na espectacularização e na raunch culture, comportaram uma maior visibilidade do movimento nos media, mas a falta de um argumento central, de um adversário claro e de um mote diferencia a SlutWalk de novos movimentos grassroot como os Indignados ou o Occupy.

Faltava ainda questionar o modo como estes grupos SlutWalk tinham sido criados. O capítulo 6 revela a importância
Periódico do Núcleo de Estudos e Pesquisas sobre Gênero e Direito Centro de Ciências Jurídicas - Universidade Federal da Paraíba V. 6 - Nº 01 - Ano 2017 - Mídia, Gênero \& Direitos Humanos SSN | 2179-7137 | http://periodicos.ufpb.br/ojs2/index.php/ged/index

do recrutamento de líderes e de indivíduos com desejo de apoiar a ideia via social media. Um traço distintivo apareceu sob o tópico de 'horizontalismo' interno aos grupos enquadrado numa estratégia plural, sem liderança central, não-hierárquica e com espaço para debate entre os membros. Contudo, nem todos os grupos optaram por estratégias de gestão coletivas e partilhadas, já que alguns preferiram formar hierarquias e delegar tarefas especializadas a determinados membros. Além disso, a estratégia de promoção de conteúdos revelou diferentes níveis de (in)experiência em modelos tão distintos como aqueles assentes na heurística do ‘aprender fazendo' ou no aproveitamento do conhecimento especializado de cada membro.

Mas o que distinguiu estas mobilizações online daquelas que se revestem de um caráter tradicional? Como transitam para as ruas? Como é que os diferentes coletivos se relacionam? E como é que os indivíduos participam nas redes? No capítulo 7, Mendes discute as inovações das mobilizações no século XXI, os ciberativismos e os contrapúblicos em rede. A constituição de novos grupos SlutWalk em torno do grupo 
central de Toronto resultou na formação de grupos-satélite, tendo como efeito latente o domínio central pela SlutWalk Toronto através da utilização dos seus símbolos, logótipos, cores, bandeiras e hashtags, ou seja, uma ação de branding que conferiu uma coerência identificativa global do movimento. Esta contra-esfera de protesto foi também usada para que os vários protestos SlutWalk promovessem outras iniciativas, incorporassem diferentes estratégias possibilitadas pelo ciberativismo (e.g., divulgação de hashtags, imagens e vídeos), promovessem ações noutras cidades e até intensificassem a articulação com outras organizações/coletivos feministas. Todavia, esta abertura à discussão gerou novas consequências decorrentes da utilização das redes sociais online, tais como o cibersexismo e o trolling. As arenas públicas e os espaços abertos de discussão permitem a entrada de vozes dissonantes e de algumas que visam unicamente desestabilizar, provocar e descredibilizar as comunidades online. As respostas das diferentes organizações consistiram em apagar os comentários de trolls, elucidar sobre as questões colocadas ou até permitir que a própria comunidade respondesse a tais tópicos.

Como nota final, e atendendo à complexidade da temática, abarcar oito espaços territoriais diferentes permitiu registar semelhanças e diferenças na forma como a SlutWalk se organizou e demonstrar a máxima 'pensar global e agir local'. Esta oscilação entre o modo como a SlutWalk se tornou global e como se adaptou às realidades locais numa estratégia glocal refletiu-se num conjunto plural de organizações, significados e mediações. Contudo, globalização e glocalização não deixam de ser estratégias neoliberais. A utilização dos corpos e a ligação à palavra slut contribuíram para o aproveitamento capitalista dos média através da veiculação de imagens que transmitiam um choque suave mas, por outro lado, permitiram ao movimento um vasto acompanhamento mediático, visibilidade e notoriedade. Este facto contribuiu para que a informação chegasse ao público em geral, com o efeito latente de a SlutWalk ter ficado de fora dos espaços dedicados às hard news e relegada para as soft news. Aqui, os média feministas contribuíram largamente para contestar e acrescentar informação à 


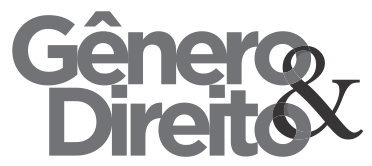

raunch culture jornalística, de visualização e espectacularização que retirou a essência do protesto, também ele apelativo ao male gaze e promotor dessa mesma cultura. Embora tenham endereçado inúmeras críticas à SlutWalk, os média feministas apresentaram uma posição genérica de apoio, discutindo investimentos políticos no feminismo, prioridades, estratégias e tácticas diferenciadas de forma a atingir a mudança social pretendida. E fizeram-no através do recurso aos mesmos formatos dos média corporativos (e.g., texto, imagens e vídeo) para demonstrar a diversidade dos agentes de protesto, tendo criado, por conseguinte, as suas contra-memórias e a (re)significação do movimento. Mesmo perante a posição global de apoio dos média mainstream aos protestos SlutWalk (o que foi surpreendente para Mendes), países como a Índia, a África do Sul e a Austrália demonstraram posições mais críticas sobre o movimento ao questionarem a sua necessidade e as suas formas de atuação, enquanto em Singapura se redefiniu as ações de rua da SlutWalk. Portanto, a hegemonia não deixa de ser hegemónica, mesmo em protestos sociais. E glocalismos não são, por si só, formas de
Periódico do Núcleo de Estudos e Pesquisas sobre Gênero e Direito Centro de Ciências Jurídicas - Universidade Federal da Paraíba V. 6 - Nº 01 - Ano 2017 - Mídia, Gênero \& Direitos Humanos SSN | 2179-7137 | http://periodicos.ufpb.br/ojs2/index.php/ged/index

contestação social. Assim, a diversidade teórica demonstra que não estamos perante um livro de apologia mas de argumentação crítica sobre a SlutWalk, defendendo e sustentando a sua pertinência. Todavia, outro dos pontos fortes do livro, a sua metodologia, resultou também num dos seus pontos fracos. A combinação de sistemas de metodologias complementares e integradas gerou, por vezes, ruído epistemológico: a menção de diversos exemplos, provindos de diferentes variáveis, obtidas através de diferentes técnicas, não resultou na inteira clarificação dos elementos sustentados. Também o enfoque constante nos social media (existem media que não sejam sociais?) merecia uma maior discussão atendendo à sua pluralidade. Afinal de contas, a SlutWalk organizou a sua cobertura online numa forma muito similar a qualquer organização: recorreu à sua rede de seguidores/participantes para promover a sua ideia.

Em suma, a SlutWalk nem sempre foi coerente. Se foi global, foi também glocal. Se emancipou grupos de mulheres, apelou também ao male gaze. Se foi inovadora, foi também reificada. Se criticou posições neoliberais, foi também 

Centro de Ciências Jurídicas - Universidade Federal da Paraíba V. 6 - Nº 01 - Ano 2017 - Mídia, Gênero \& Direitos Humanos ISSN | 2179-7137 | http://periodicos.ufpb.br/ojs2/index.php/ged/index ideologicamente a elas conotada. Se revitalizou o feminismo, também o aguou. Se existiu online, marcou também presença nas ruas. Se foi horizontal, foi também hierarquizada. Ainda assim, a SlutWalk fez a diferença no alerta para a violência sexual, captando um indivíduo de cada vez, em diferentes partes do globo, simplesmente: “Because We've Had Enough". 